\title{
LA ORDENACIÓN Y GESTIÓN DE LAS HUERTAS MEDITERRÁNEAS ESPAÑOLAS. EL TIEMPO DE LA(S) POLÍTICA(S)
}

\author{
Juan Romero y Carme Melo \\ Instituto Interuniversitario de Desarrollo Local y Departamento de Geografía. Universitat \\ de València
}

\section{RESUMEN}

Las grandes Huertas mediterráneas españolas afrontan un futuro incierto. Varios procesos convergentes comprometen ese futuro: reducción de la superficie tradicional, pérdida de rentabilidad y escasas garantías de relevo generacional en las explotaciones, contaminación, consumo de suelo para trazado de infraestructuras y clasificación de suelo agrícola como urbanizable. Las distintas administraciones con competencias sobre las Huertas han permitido o propiciado durante décadas el avance de estos procesos. Ninguna de ellas ha demostrado la suficiente voluntad política para adoptar planes territoriales y estrategias de coordinación a escala metropolitana que garantizasen la protección de estos espacios periurbanos de singular valor. La conservación de las Huertas requiere una nueva forma de entender la cultura del agua, del territorio y del paisaje. Para mantenerlas vivas, los agricultores han de continuar siendo los protagonistas. Hay posibilidades de futuro: desde la agricultura y la ganadería biológica, saludable y de calidad orientada a la demanda urbana próxima, hasta la formación o el turismo rural. La función social requerida a los agricultores será, en algunos casos, distinta a la tradicional. En ese contexto, los poderes públicos han de imaginar un nuevo contrato social con los agricultores.

Palabras clave: Huertas Mediterráneas, Valencia, Murcia, Paisajes culturales, Ordenación territorial, Gobernanza 


\section{ABSTRACT}

The planning and management of Spanish Mediterranean Huertas. The time of policies

Spanish Mediterranean Huertas face an uncertain future. They are affected by several processes that exert pressure of them, namely, the reduction of the traditional surface, a loss of profitability, low perspectives for generational renewal, pollution, non-agricultural land uses, like industrial activities and infrastructures, and the conversion of rural land into land suitable for urban development. Public administrations with jurisdiction over the Huertas have long permitted or encouraged these processes. None of them has had enough political will so as to adopt territorial plans and coordination strategies at the metropolitan scale to guarantee the protection of these peri-urban singular spaces. The conservation of Huertas requires a new understanding of water culture, landscape and territory. For them to be kept alive, farmers should be their main actors. Future possibilities include organic agriculture and farming to satisfy urban demand, education and tourism. Sometimes farmers will have to play a social function different from the traditional one. In this context, a new social contract with farmers will be needed.

Keywords: Mediterranean Huertas, Valencia, Murcia, Cultural landscapes, Territorial Planning, Governance

\section{INTRODUCCIÓN}

Las Huertas periurbanas poseen una gran importancia estratégica relacionada con la producción de alimentos (Beltrán, 2012) y un elevado valor históricopatrimonial debido a sus complejos sistemas de regadío tradicionales (Glick, 1970; Burriel, 1971; Courtot, 1986). Pero más allá de la importancia que les confieren estos rasgos, se trata de paisajes culturales tradicionales que constituyen un elemento de identidad basado en siglos de historia de la cultura y que testimonia el paso de diferentes pueblos que han dejado su huella en ellos (Antrop, 1997; Vos y Meekes, 1999; Barbera y Cullotta, 2012). Son a la vez historia de la cultura, de la tecnología, de la organización social, de las estructuras de poder, de la agricultura y del paisaje.

Como se recoge en el Informe Dobris, comisionado por la Agencia Europea del Medio Ambiente en 1995, únicamente quedan seis Huertas mediterráneas en Europa (Stanners y Bourdeau, 1995). En este trabajo nos centramos en dos de ellas, las Huertas de Valencia y Murcia, en tanto que escenario privilegiado para poder analizar lo que ha pasado en muchas grandes áreas metropolitanas españolas durante los últimos años: expansión caótica y masiva del urbanismo residencial, localización desordenada de actividades industriales y de servicios, especulación del suelo y degradación medioambiental. Estas son las consecuencias visibles de la ausencia de planificación a escala metropolitana, de la incuria de las administraciones autonómicas concernidas, que haciendo dejación de sus 
competencias en materia de ordenación del territorio no han querido establecer marcos de ordenación y gestión a escala supralocal, y de la voracidad de decenas de corporaciones locales que no han reparado en las consecuencias irreversibles del proceso.

La (des)protección de las grandes Huertas mediterráneas periurbanas españolas de Valencia y Murcia y la ausencia de iniciativas políticas de coordinación a escala metropolitana sintetizan muy bien el riesgo que supone carecer de mecanismos coherentes eficaces de ordenación y gestión en la segunda década del siglo XXI (Romero, 2009; Romero y Francés, 2012). La atención al futuro de estos regadíos históricos mediterráneos trasciende con mucho los enfoques socioeconómicos, de trazado de infraestructuras, medioambientales o paisajísticos en espacios rurales periurbanos, para situarse en el plano de la necesaria ordenación y gestión integrada de unos paisajes culturales excepcionales mediante instrumentos adecuados y desde la escala supramunicipal. Pocas ciudades europeas disponen de entornos tan singulares y valiosos; pero la realidad es que hasta ahora, nadie se ha ocupado de su protección. Ahora bien, es posible que algunos de los cambios producidos tras las elecciones municipales y autonómicas de mayo de 2015 den paso a una nueva etapa en materia de ordenación del territorio, en la gestión de paisajes culturales y en la protección medioambiental de estos espacios tan valiosos y, a la vez, sometidos a tantas presiones.

\section{CAMBIOS RECIENTES Y SITUACIÓN ACTUAL}

Las Huertas se encuentran en constante evolución. Son el resultado de siglos de interacciones entre los seres humanos y la naturaleza, de transformaciones en los modelos agrícolas y usos del suelo, pero también en las necesidades humanas. Con todo, es en el siglo XX, con el triunfo de la modernidad sobre la tradición, cuando han empezado a experimentar cambios dramáticos relacionados con el crecimiento de la ciudad hacia la periferia y la ocupación del suelo (CárcelGarcía et al, 2014). En la actualidad, su condición de agricultura periurbana sigue ejerciendo una enorme presión sobre las Huertas tradicionales y sus rasgos de identidad. A continuación analizaremos cuáles han sido los principales cambios que, a nuestro juicio, amenazan la propia existencia de estos sistemas agrícolas históricos.

\section{Reducción de la superficie tradicional}

La superficie tradicional de las Huertas se ha reducido considerablemente debido a la especulación del suelo y al desarrollo urbanístico. La mayor parte de las acequias han visto su perímetro regado disminuido de tal manera que en algunos casos es ya testimonial. En ciertos tramos la zona regable ha desparecido 
por completo y, en otros, únicamente subsisten áreas inconexas de huerta residual susceptibles de desaparecer definitivamente de producirse un nuevo ciclo expansivo de la construcción residencial.

La Huerta de Valencia tenía 20.000 hectáreas en 1960. La Estrategia Territorial de la Comunidad Valenciana de 2011 reconoce la pérdida de 1.500 hectáreas a lo largo de los últimos veinte años, aunque estudios realizados por colectivos ciudadanos, como la plataforma Per l'Horta revelan cifras mayores (Montiel y García de Leonardo, 2014). Una investigación reciente sobre los cambios espaciales producidos en la Huerta de Valencia entre 2008 y 2013 identifica una pérdida del $6,5 \%$ de la superficie cultivable debido, principalmente, al abandono de tierras (Argyelan et al, 2014).

La Huerta de Murcia presenta un panorama similar. Los cambios más significativos que se han producido en las últimas décadas son la conversión de suelo agrícola en suelo urbano debido a la expansión de la ciudad de Murcia y a los asentamientos residenciales dispersos. El número de habitantes en los municipios que integran la Huerta está aumentando. Si se mantiene esta tendencia, la ciudad de Murcia perderá el 10\% de su población en los próximos treinta años, mientras que las pedanías de la Huerta seguirán aumentando, hasta el punto de llegar a tener casi el mismo número de habitantes. Es importante hacer hincapié en que el desarrollo urbano se ha producido, a menudo, al margen del planeamiento. Entre un $20 \%$ y un $40 \%$ de las viviendas edificadas son ilegales, y el porcentaje de infraestructura industrial construida sin licencia es aún mayor. Los planes recientes legalizan algunas de estas viviendas, poniendo de relieve cuál ha sido la actitud de las administraciones públicas hacia la protección de la Huerta murciana (Mata y Fernández, 2010; Martí y Moreno, 2014).

\section{Expectativas inciertas para la actividad agropecuaria}

En su combate desigual con la urbanización del suelo, las expectativas para la actividad agropecuaria son muy inciertas. Las Huertas tradicionales mediterráneas están experimentando un descenso de las actividades productivas, en un contexto de crisis de la agricultura a pequeña escala (Cortina y Zapata, 1993; Romero y Francés, 2012). El abandono de tierras y los nuevos usos del suelo, incluyendo actividades recreativas, jardinería y autoproducción, están contribuyendo a la disminución de la producción agrícola. La falta de rentabilidad de muchas cosechas, la creciente inseguridad y los episodios de vandalismo, el desconcierto de unos titulares de explotación envejecidos y con dificultades para trasmitir la explotación a un familiar directo más joven, y la reducción de la ventaja comparativa derivada de la proximidad a un gran centro urbano respecto a otras producciones hortofrutícolas industriales que ahora llegan sin dificultad, explican el abandono de tierras y hacen que el futuro se haya orientado en 
muchos casos hacia la introducción de otros cultivos, como los cítricos (Moreno et al, 2010). Estos cultivos permiten externalizar los trabajos, practicar la agricultura a tiempo parcial y mantener así un patrimonio en expectativa de ser vendido como suelo urbano o industrial. Sin embargo, ello se está produciendo en detrimento de algunos de los cultivos tradicionales característicos de la Huerta.

\section{Contaminación}

Los niveles de contaminación de las Huertas son muy elevados. Existen múltiples puntos de vertido incontrolado de residuos urbanos e industriales. Muchos canales de riego en la Huerta de Valencia funcionan de hecho como alcantarillado urbano o como puntos de vertido sin depuración de polígonos o de actividades industriales. De otra parte, es conocido que el río Segura ha funcionado en su parte baja como un gran colector urbano e industrial y que la salinización de los campos de cultivo, la calidad de las aguas y la contaminación de aguas subterráneas son un problema que arrastra la Huerta de Murcia desde hace décadas. El uso indiscriminado de pesticidas y el sobretratamiento del suelo con fertilizantes nitrogenados ha contaminado las aguas subterráneas hasta unos niveles (superiores a los 100, 150 e incluso los $200 \mathrm{mg} /$ litro en algunos municipios) que las hace inservibles para el consumo humano durante generaciones. Todo ello pese a contar con Directivas comunitarias, reglamentos del gobierno central, y reglamentos y órdenes regionales que obligan a desarrollar políticas de reducción de contaminación difusa por nitratos.

Merece la pena detenerse un instante en este último punto por su relevancia y sus implicaciones en el terreno de las políticas. Si bien es cierto que la relación de cuestiones que provocan la contaminación o la intoxicación, invisible, difusa, lenta y silenciosa es tan amplia como la falta de información veraz y completa, no es menos cierto que determinados procesos no controlados van socavando la salud de las personas porque ningún responsable público se atreve a afrontar la situación con medidas que serían impopulares para determinados sectores de negocio o grupos de presión. En muchas ocasiones porque ni siquiera existe conciencia ciudadana de la verdadera magnitud del problema, por tanto ¿para qué hacer nada si nadie lo reivindica? En otras, porque las consecuencias en procesos medioambientales o de salud alimentaria se manifiestan a medio y largo plazo, mientras que el tiempo electoral y político es a corto plazo y nadie quiere asumir el coste de la adopción de determinadas medidas a menos que sea absolutamente imprescindible, y aún así con muchas limitaciones.

Un buen ejemplo es el de la contaminación de aguas superficiales y subterráneas por aguas residuales y por nitratos. La aplicación inadecuada de fertilizantes nitrogenados en la agricultura de regadío y la dispersión de efluentes procedentes de residuos urbanos e industriales contaminan las aguas destinadas 
al consumo humano o al riego de hortalizas que consumimos pensando, paradójicamente, que se trata de alimentos saludables (IGME, 1985; IGME, 1998). Los acuíferos subterráneos en estas áreas de regadío presentan niveles superiores a 100 miligramos por litro de NO3. Algunas se acercan a los 200 miligramos por litro. La directiva comunitaria 91/6767/EEC de diciembre de 1991 establecía que los niveles superiores a $50 \mathrm{mg} /$ litro son perjudiciales para la salud. Más tarde se rebajó el nivel máximo a $25 \mathrm{mg} /$ litro. El propio Gobierno Valenciano, en su Decreto 13/2000 de 25 de enero, incluía en su relación de zonas vulnerables afectadas por la contaminación de acuíferos por nitratos la mayor parte de los municipios ubicados en la Huerta.

\section{Dotación de infraestructuras y equipamientos}

La dotación de infraestructuras y equipamientos ha supuesto también una reducción notable del espacio productivo. Es el caso de grandes infraestructuras estatales y de corredores y distribuidores metropolitanos que atraviesan y ocupan algunos de los espacios de huerta milenaria mejor conservados. A modo de ejemplo, cabe citar la construcción de la autopista A-7 a lo largo de la costa mediterránea, el tren de alta velocidad (AVE) o la carretera CV-300 en Valencia, y la autopista A-30 en Murcia. En otros casos, la ubicación de servicios educativos o las ampliaciones de servicios portuarios también han provocado pérdidas irreversibles. El avance de los últimos veinte años, las futuras previsiones de crecimiento en los municipios de las dos grandes áreas urbanas de Murcia y Valencia y la localización desordenada y descoordinada de actividades industriales, en muchos casos sin garantía en cuanto a depuración de vertidos, son una amenaza cierta para las Huertas históricas.

Este es otro buen ejemplo que evidencia el alto grado de descoordinación entre administraciones y entre departamentos de un mismo gobierno. Unos y otros anuncian y proyectan nuevos trazados con fuerte impacto territorial, ignorando actuaciones y propuestas de otros departamentos empeñados a la vez en proteger y conservar esos mismos espacios. Paradójicamente, la mayor amenaza para un paisaje cultural tan valioso y con tanta carga simbólica vendrá del desarrollo de infraestructuras. Por lo tanto, procede de la misma esfera pública que, desde otras instancias, persigue su protección.

\section{EL MARCO INSTITUCIONAL: EL FRACASO DE LA PLANIFICACIÓN Y DE INICIATIVAS POLÍTICAS DE COORDINACIÓN Y COOPERACIÓN A ESCALA METROPOLITANA}

La relación de seminarios, Planes seguidos del calificativo «verde»o «sostenible» y planes municipales de especial protección que han visto la luz durante los pasados años y que abogan por la defensa y protección de las Huertas mediterráneas es interminable. Existen incluso instrumentos que, sin obligar de forma 
imperativa, sí pretenden incorporar una nueva cultura del territorio y otras formas de proteger y gestionar estos espacios tan vulnerables. Es el caso, por ejemplo, del Dictamen del Comité Económico y Social Europeo sobre Agricultura Periurbana (CESE, 2004), la Carta de la Agricultura Periurbana (Parc Agrari del Baix LLobgregat et al, 2010) y la legislación española sobre desarrollo rural sostenible (especialmente la Ley 45/2007 para el Desarrollo Rural Sostenible). Sin embargo, las directrices y recomendaciones contenidas en estos documentos no han sido desarrolladas legislativamente, de modo que «[1]a realidad de la agricultura periurbana, sus funciones y especificidades, ha quedado así ausente de la 'gran política'» a ambos niveles, europeo y estatal (Montiel y García de Leonardo, 2014: 4). Ningún gobierno democrático ha tomado una sola iniciativa eficaz de forma global, es decir, a escala metropolitana, que naciera con vocación de alterar esta deriva de desgobierno territorial y de progresiva destrucción de dos de los paisajes culturales más formidables de la cuenca del Mediterráneo. Iniciativas eficaces, se entiende, que además estén fundamentadas en la realidad y no en la creencia nostálgica de que cualquier tiempo pasado fue mejor o en la pura utopía urbanita.

Para una mejor comprensión del estado actual de la cuestión, piénsese en el gran número de centros con capacidad de decisión política sobre el mismo territorio y con fuerte impacto territorial. Por ejemplo, en el perímetro de la Huerta de Valencia existen 45 municipios con sus correspondientes planes de ordenación, más el Consell Metropolità de l'Horta, la Diputación Provincial, al menos cinco Consejerías con competencias (no siempre con el exigible grado de coordinación entre departamentos o entre áreas de un mismo departamento), la Confederación Hidrográfica del Júcar, dos ministerios inversores con sus organismos y las comunidades de regantes. El resultado es que todos deciden y nadie es responsable de las consecuencias.

Las transformaciones del espacio periurbano de la Huerta de Murcia han desestructurado casi por completo el área. El planeamiento ha permitido durante demasiado tiempo la urbanización de la Huerta. Los Planes Generales de Ordenación Urbana de 1977 y 2001 perpetúan una ideología basada en la urbanización y la transformación en lugar de apostar por la conservación de la ciudad existente y de su Huerta (Martí y Moreno, 2014). El Plan de Ordenación de la Huerta de Murcia, sugerido por expertos desde hace años (Mata y Fernández, 2003), no ha contado con el impulso imprescindible del gobierno regional y ha quedado en mero diagnóstico. También han sido ignoradas las reiteradas peticiones por parte de la Asociación para la Conservación de la Huerta de Murcia (Huermur), quien desde su creación en 2007 viene denunciando la situación de deterioro de la Huerta y reclamando la elaboración de un Plan de Protección y Recuperación de la Huerta que cuente con una amplia participación ciudadana. 
El valor de la Huerta de Valencia en tanto que patrimonio histórico, cultural, natural y agrícola, así como la necesidad de evitar daños ulteriores, fueron proclamados en la Opinión del Consell Valencià de Cultura, órgano consultivo y asesor del gobierno autonómico, y en la Iniciativa Legislativa Popular promovida por asociaciones ecologistas, culturales y vecinales en 2001, que pedía una ley de protección de la Huerta y que fue rechazada por el parlamento valenciano a pesar de haber obtenido más del doble de las firmas requeridas. Probablemente como resultado del interés y la movilización social, la administración autonómica acordó que había de diseñarse un plan especial de protección para la Huerta (Montiel y García de Leonardo, 2014). Así, el Plan de Acción Territorial de Protección de la Huerta de Valencia fue hecho público en 2008 (Generalitat Valenciana, 2008; Muñoz, 2009). El Plan habría resuelto algunos de los problemas detectados si hubiese incorporado, mediante una ley del parlamento regional, instrumentos de protección supramunicipales y una coordinación efectiva entre distintos departamentos con gran capacidad estructurante del territorio. Muy en especial, además de Agricultura, el que tiene asignadas las competencias de Infraestructuras y el que reúne las de Territorio, Vivienda, Agua y Paisaje. Hubiera sido necesario, además, haber contado con el concurso ineludible de los gobiernos locales concernidos. Pero nada de esto ocurrió.

Algunas de las figuras que ese nuevo Plan Sectorial incorporaba estaban bien concebidas, sintonizaban con los contenidos y postulados que abogaban por una nueva cultura del paisaje y una gestión más prudente del territorio y sugerían propuestas realistas y orientadas a garantizar el mantenimiento de la actividad agropecuaria como condición necesaria. Como documento inicial para la discusión y la participación, podría haber sido un punto de partida para impulsar el diálogo con el resto de agentes sociales, especialmente agricultores, vecinos y colectivos ciudadanos, e intentar incorporar las demandas de estos. Hubiera podido prosperado de existir el compromiso político de desarrollar nuevos instrumentos de protección y un amplio abanico de políticas públicas para revitalizar económicamente la Huerta con criterios de sostenibilidad. Haciendo de la búsqueda de amplios consensos sociales y políticos para aprobar una ley de protección de la Huerta su primer objetivo. Partiendo de un buen conocimiento de la gran diversidad de situaciones y de los serios obstáculos existentes. Con un enfoque metropolitano flexible y adaptado a un contexto cultural específico. Y conscientes de que había llegado el momento de garantizar la continuidad de un espacio agrícola periurbano de alto interés estratégico y un paisaje cultural milenario de elevado valor simbólico y gran proyección internacional.

Mientras el departamento responsable impulsaba el Plan de Acción Territorial, otras instituciones regionales y ministerios del gobierno central anunciaban propuestas de nuevas actuaciones y trazados de infraestructuras sin coherencia alguna con los contenidos del Plan. Y muchos gobiernos locales se 
apresuraron a aprobar nuevas propuestas de planeamiento al margen y con carácter previo a lo que un futuro Plan Territorial supramunicipal pudiera indicar con carácter orientativo o vinculante. En esa situación se encontraba, por ejemplo, la tramitación de un PAI que preveía la construcción de 13.446 nuevas viviendas en el pequeño municipio de Catarroja, ubicado en el sur de la Huerta de Valencia, y la del proyecto de reforma del Plan General de Ordenación Urbana de la propia ciudad de Valencia, cuya trascendencia sobre el conjunto del área que se pretende proteger es indudable. Pero también otros municipios del área metropolitana se apresuraron a modificar su planeamiento con la intención de anticiparse a posibles restricciones de ulterior crecimiento urbanístico que pudiera incorporar un Plan Territorial y situar así a la administración regional ante una situación de hechos consumados. En cualquier caso, el Plan de Acción Territorial para la Protección de la Huerta de Valencia fue descartado en 2010. Y, posteriormente, la Estrategia Territorial de la Comunidad Valenciana de 2011 eliminó la posibilidad de que el desarrollo local y el planeamiento urbanístico siguieran las directrices establecidas en el Plan de Acción Territorial, con lo que la conservación de la Huerta de Valencia no está garantizada (Montiel y García de Leonardo, 2014).

Los casos de Murcia y Valencia sugieren que el problema principal al que se enfrentan las Huertas históricas ha sido la falta de voluntad política por parte de los gobiernos autonómicos. Asimismo, son una excelente expresión y un buen reflejo de una cultura social mayoritaria «productivista» y de la pervivencia de esa «marcada vocación constructivista» (Rodríguez y Vicente, 2009) mayoritaria durante años en muchos gobiernos locales en España. Una vocación que anticipa riesgos para el futuro puesto que responsables políticos de muchas corporaciones locales ya han descontado el actual momento que entienden coyuntural y prevén nuevos crecimientos desmesurados una vez superada la actual fase de recesión económica. Naturalmente, incluso sin disponer de Planes de protección de paisajes culturales singulares o de espacios metropolitanos, siempre queda en manos de la administración regional competente la posibilidad de sugerir modificaciones al planeamiento municipal e incluso de no aprobar determinadas propuestas, pero es discutible que al amparo de la autonomía municipal pudieran bloquearse si la tramitación cumple escrupulosamente con todos los procedimientos. De ahí la importancia de contar con directrices vinculantes de ordenación supralocales, de ahí la gran responsabilidad de los gobiernos y parlamentos regionales y de ahí la gran relevancia de contar con mecanismos eficaces de coordinación y cooperación.

Durante los últimos años hemos conocido en España una auténtica profusión de documentos denominados Planes, Estrategias o Directrices Territoriales a escala regional. Desde ese punto de vista, nadie podrá negar sustanciales avances en materia de pensamiento y nuevos enfoques. Cosa muy distinta es 
que muchos de esos documentos hayan demostrado alguna eficacia que haya ido más allá de su publicación y publicitación tanto en el ámbito de la gobernanza como, sobre todo, en el del gobierno del territorio. Hasta ahora bien puede hablarse del fracaso generalizado de iniciativas encaminadas a reforzar la escala regional o subregional en la ordenación del territorio. También cabe evaluar en clave de fracaso la casi inexistente cooperación (formal e informal) entre ciudades y entre territorios próximos homogéneos. La cooperación interregional, que ahora encuentra mayores posibilidades tras la reforma de Estatutos de Autonomía, sigue siendo uno de nuestros retos geopolíticos más sobresalientes.

Ha sido este un periodo que se ha prolongado casi década y media, y en el que los textos legales han librado una desigual batalla con la existencia de un contexto institucional y de una cultura territorial productivistas, con un ciclo económico expansivo y con una enorme facilidad para obtener financiación con bajo interés. Si en esas condiciones los textos legales no eran claros y vinculantes, no existía voluntad de aplicarlos o favorecían sin restricciones la urbanización masiva y desordenada en suelo rústico, era previsible el resultado. En ausencia de marcos orientadores vinculantes a escala supramunicipal el territorio se ordena (o se desordena) por agregación, yuxtaposición y superposición segmentada. Y son los actores (públicos y privados) presentes en cada territorio en la escala local, que muchas veces funcionan en paralelo o de forma contradictoria, quienes «dictan» las leyes que verdaderamente inciden en esos territorios. Si además de ello determinadas normas permiten sacar el urbanismo de los planes de ordenación locales, como ha sido nuestro caso desde 1998 hasta 2008 durante la vigencia de la legislación liberalizadora en materia de suelo, en determinados contextos pueden cobrar forma situaciones tan excepcionales e insostenibles como las vividas en España (Romero et al., 2013).

No hemos contado con buenos instrumentos de gobierno del territorio (o no se han querido aplicar) y tampoco hemos sido capaces de imaginar nuevas formas de buen gobierno territorial. Y en esta indeterminación política y normativa entre lo tradicional y lo nuevo, los gobiernos locales (contando con la cooperación imprescindible de muchos gobiernos regionales) han desarrollado su planeamiento con desmesura y sin coherencia. Han sobrado documentos y ha faltado enfoque estratégico y voluntad política. Pero nadie puede alegar ahora desconocimiento. Hace tiempo que se advierte de las consecuencias indeseables de las dinámicas territoriales alentadas en España. También hace tiempo que diversos organismos internacionales ofrecen información que ayuda a entender las causas del fracaso o del éxito de muchas de estas iniciativas sobre desarrollo territorial sostenible que parten de enfoques estratégicos. Y las explicaciones extraídas de la experiencia internacional, bien pudieran ser de aplicación en muchos de los casos analizados. 
Muchas de las estrategias, como ya subrayó Joan Prats (2003), fracasaron por algunas de las razones siguientes. En primer lugar, no pretendieron o no fueron capaces de integrarse en el sistema de planeamiento operativo existente, funcionaron aisladas y al margen, y no consiguieron la eficacia necesaria. Una estrategia de desarrollo sostenible no es una estrategia o un plan más, sino un espacio y un proceso capaz de integrar y de integrarse en las estrategias y los planes existentes. Además, muchas no eran estrategias verdaderas, sino listas -a veces muy bien hechas- de deseos faltadas de la concreción necesaria en objetivos estratégicos, metas formuladas debidamente y acciones específicas muy comprometidas y presupuestadas. Una estrategia no es un inventario de todo lo que hay que hacer, sino una selección de objetivos, metas, acciones, entre muchos otros posibles. Por lo tanto no se trata de una elaboración técnica, sino genuinamente política, en la cual los técnicos solo pueden coadyuvar. Por otra parte, muchas se elaboraron sobre la base de participación insuficiente, fueron incapaces de comprometer al sector privado y las organizaciones sociales que resultaban necesarias para la consecución de cada objetivo y experimentaron que sólo con la acción gubernamental no basta. Por último, otras fracasaron porque no apoyaron los procesos ya existentes y quisieron empezar algo nuevo y diferente.

\section{EL TIEMPO DE LAS POLÍTICAS}

El tiempo de los estudios y de los diagnósticos ya pasó. Ahora es el tiempo de las políticas. Conocemos bien los procesos convergentes que suponen una amenaza para la Huerta: pérdida de rentabilidad y escasas garantías de relevo generacional en las explotaciones, inseguridad y vandalismo, ausencia de un modelo de comercialización y de consumo saludable centrado en la importancia de lo local, contaminación, trazado de infraestructuras y expansión desordenada del espacio urbano. Ahora se trata de pasar de las palabras a los hechos. Para ello, proponemos algunas recomendaciones que podrían ser adoptadas para la protección de las Huertas históricas mediterráneas.

\section{Impulsar Planes Territoriales a escala metropolitana}

El retroceso será irreversible si no se impulsan Planes Territoriales a escala metropolitana que establezcan regulaciones pormenorizadas de protección especial para suelos agrarios de alto valor agrícola, patrimonial y paisajístico. Así lo atestiguan también numerosos estudios (Mata y Fernández, 2010; Mata, 2011; Montiel y García de Leonardo, 2014; Muñoz, 2009; Romero y Farinós, 2012). Es imprescindible contar con un marco legal que permita el impulso de planes territoriales metropolitanos que coordinen el planeamiento municipal futuro como condición necesaria. Sin una política territorial supramunicipal 
cada municipio adoptará, como hasta ahora, sus propias directrices y planeamiento del suelo, y cada unidad de las diversas administraciones competentes seguirá impulsando medidas en muchos casos contradictorias. El resultado será sencillamente caótico, el proceso de reducción de suelo agrícola de alto valor seguirá en cuanto el mercado de la vivienda recupere un mínimo de actividad y el declive de las Huertas será irreversible.

El propio bloque de constitucionalidad y las reiteradas sentencias del Tribunal Constitucional facultan a las Comunidades Autónomas a poder impulsar este tipo de instrumentos normativos sobre la base del principio de coordinación. Sin menoscabo del respeto a la autonomía municipal, pero con capacidad de redactar normas vinculantes que establezcan la obligatoriedad de que el planeamiento municipal se adapte y recoja en su categorización del suelo no urbanizable de especial protección zonas definidas con la coherencia requerida para el conjunto de las áreas periurbanas. Solamente en esa escala y con ese tipo de instrumentos se podrían abordar planes integrales de protección de las Huertas en aquellas áreas susceptibles de ser protegidas con garantía de estabilidad futura. Ello implicaría además desplegar políticas metropolitanas de depuración integral de aguas, control de vertidos, planes de modernización del regadío tradicional, iniciativas de coordinación de polígonos industriales y de dotación de servicios, planes incentivadores de agricultura y ganadería biológica y saludable, planes de reducción de abonos nitrogenados y de tratamientos de productos fitosanitarios, y planes de rehabilitación de patrimonio rural, de la red de caminos y de elementos del sistema hidráulico.

\section{Promover la cooperación de los agricultores y garantizar la estabilidad de las explotaciones}

La conservación de las Huertas debe hacerse apelando a valores que se asientan en un nuevo modelo de comercio y de consumo y en una nueva cultura del agua, del territorio y del paisaje. Para mantenerlas vivas y dar contenido a su carácter multifuncional, los agricultores han de continuar siendo sus auténticos protagonistas y los únicos que podrán mantenerlos vivos. Hay que impulsar iniciativas desde la esfera pública que hagan posible que la actividad agrícola sea una opción viable tanto para atraer a nuevos agricultores como para asegurar la sostenibilidad de quienes ya se encuentran presentes en el territorio. Será muy importante, también, diseñar políticas adecuadas para atraer a las generaciones más jóvenes y a las mujeres hacia la agricultura (Montiel y García de Leonardo, 2014). Como han demostrado diversas investigaciones, los proyectos y planes que persiguen la protección del paisaje periurbano sin contar con los agricultores están abocados al fracaso o, aún peor, al riesgo de entenderlos como 
espacios temáticos para ser visitados (Mata y Fernández, 2010; Muñoz, 2009; Giacché y Mazzocchi, 2011).

En este sentido, las políticas públicas y el planeamiento urbanístico han de buscar el consenso y la cooperación de los agricultores, así como garantizar la estabilidad y rentabilidad de las explotaciones agropecuarias. Las posibilidades son múltiples, por ejemplo, la introducción de mecanismos económicos incentivadores o de compensación para aquellas explotaciones que hayan de mantenerse por su valor territorial, cultural o paisajístico, el fomento de la agricultura y la ganadería ecológicas orientadas a la demanda urbana próxima, la creación de nuevos certificados de denominación de origen, planes de recuperación del patrimonio cultural y natural, medidas eficaces para controlar el robo de cosechas, o el desarrollo de actividades complementarias, como las relacionadas con el turismo rural o la educación medioambiental. En algunos casos, la función social requerida a los agricultores será distinta a la tradicional. Ahora se tratará de mantener vivos unos territorios porque la sociedad considera que el territorio, además de un recurso y de soporte físico para actividades, es referente identitario, es patrimonio colectivo, es cultura, es historia y es legado. En ese contexto, los poderes públicos han de imaginar un nuevo contrato social con los agricultores en estas áreas singulares.

\section{Partir de nuevos enfoques en el gobierno del territorio}

El enfoque estratégico para el desarrollo territorial sostenible supone, siguiendo a Prats (2003), nuevas maneras de pensar y de trabajar. Ello implica, ante todo, pasar de formular e impulsar un Plan fijo, que devendrá obsoleto inevitablemente, a la elaboración de un sistema operativo y adaptativo que mejore de manera constante. Asimismo, es menester superar la idea de que los gobiernos son los únicos responsables del desarrollo y reconocer que la sociedad tiene mucho que decir al respecto. El planteamiento territorial implica, además, evolucionar desde sistemas de toma de decisión controlados y centralizados a otros basados en compartir resultados y oportunidades, negociaciones transparentes, cooperación y acción concertada, y transitar desde el planeamiento sectorial al planeamiento integrado. Lo importante no son los productos (planes, normas proyectos, etc.) sino los resultados y la calidad de la participación y de los procesos de gestión. Además, el buen gobierno del territorio descansa básicamente sobre los principios de coordinación y cooperación y requiere además prestar atención al conjunto de actores sociales y económicos concernidos. Sin estas condiciones básicas, no es posible hablar de gobernanza y ninguna de ellas se da en el caso español de forma amplia y satisfactoria.

Por ello sería conveniente recuperar la cultura política del consenso y la cooperación y disponer de instrumentos claros de buen gobierno del territorio 
en la escala adecuada, para poder desarrollar principios y valores de desarrollo sostenible, cohesión y coherencia territorial, hace tiempo sugeridos desde instituciones europeas y hoy ampliamente compartidos en ámbitos académicos y técnicos. Nada de ello, todo lo contrario, entra en contradicción con el desarrollo de mecanismos de buen gobierno territorial. Lo que aquí se enfatiza es la necesidad de desarrollar, perfeccionar y clarificar nuestros mecanismos institucionales de coordinación de acuerdo con nuestro marco legal y a partir la amplia jurisprudencia existente. Insistiendo en la necesidad de que todos los poderes del Estado hagan bien sus deberes. Sin por ello restar importancia a la emergencia de nuevas formas de participación en el proceso de toma de decisiones.

Aunque tarde, parece que el debate sobre modelos territoriales ha entrado en el territorio de la política. Muchos gobiernos regionales proponen durante los últimos años debates sobre Modelos Territoriales y promueven Directrices y Estrategias que merecen atención. Nosotros defendemos la idea de que, pese a todo y con todas las reservas, esta nueva generación de Estrategias, Planes y Directrices Territoriales deben considerarse como una oportunidad. El Modelo Territorial es el mejor instrumento integrador de la escala regional porque le confiere mucha coherencia y es un buen instrumento de cooperación interregional. Su punto fuerte radica en el propio método de elaboración, discusión y aprobación consensuada de escenarios deseables de medio plazo, primero por una amplia red de actores sociales presentes en el territorio, y finalmente por los representantes democráticos de los gobiernos locales y de parlamentos regionales. De otra parte, planes territoriales a escala subregional son igualmente imprescindibles para ir dando coherencia territorial a políticas sectoriales y a planes municipales de ordenación urbana, para incorporar valores y visiones inspiradas en la nueva cultura del territorio, y para garantizar la preservación de paisajes culturales. Muchos territorios han sido muy afectados durante la última década y media y las pérdidas son ya irrecuperables, pero en otros muchos casos aún se está a tiempo de hacer las cosas mucho mejor. Y este es el caso de las Huertas.

Hay que avanzar en esta dirección. Para ello, urge, en primer lugar, un debate colectivo liderado por los gobiernos regionales capaz de construir amplios consensos básicos sobre el modelo territorial a escala regional y sobre la necesidad de contar con instrumentos de buen gobierno del territorio a escala supralocal, con especial atención a los espacios litorales, las áreas urbanas y metropolitanas y los espacios rurales. En segundo lugar, cabe apostar por una concepción estratégica basada en los principios de una nueva cultura de buen gobierno del territorio inspirada en las orientaciones de la Unión Europea en materia territorial y de gestión de espacios periurbanos. 
Consideraciones Finales: ¿UN NUEVo escenario Para las Huertas?

Las Huertas de Murcia y Valencia han participado de los mismos procesos de dispersión de actividades económicas y residenciales ocurridos en las grandes áreas metropolitanas españolas durante los últimos años. Su (des)protección, al igual que otras Huertas menores del litoral mediterráneo, obedece a varias razones, pero algunas son más importantes que otras. La superficie tradicional de las Huertas ha disminuido significativamente. La mayor parte de las acequias han experimentado importantes reducciones de su perímetro regado. Los niveles de contaminación son elevados. La dotación de infraestructuras y equipamientos ha supuesto también un retroceso notable del espacio productivo. Destacamos la ausencia de iniciativas políticas de ordenación territorial coherente a nivel regional y local, la falta de dispositivos institucionales eficaces de coordinación a escala metropolitana, la escasa cultura territorial y la ausencia de una apuesta decidida por hacer de los agricultores pieza fundamental de un modelo de producción y consumo distinto.

Las grandes Huertas históricas mediterráneas, en tanto que paisajes culturales, son el resultado de un grupo humano de agricultores y agricultoras portadores de saberes locales que durante siglos hicieron posible una organización del territorio, unos modelos de explotación y un tipo de hábitat. No obstante, insistir en la construcción de un discurso urbanita centrado en la importancia de las Huertas solo como paisaje cultural no solo es parcial sino que está abocado al fracaso o a la melancolía. Si se convierten en territorio de las clases medias urbanas, en espacios tematizado para ser visitados, en depositario de referencias románticas o idílicas por parte de quienes no tienen relación física o jurídica con ese territorio, estos espacios periurbanos desaparecerán. Su supervivencia solo será posible desde un nuevo paradigma que ponga en relación desarrollo local, producción sostenible de alimentos, consumo local, salud, gestión sostenible de recursos y garantía de precios justos para los agricultores. Lo más importante, a nuestro juicio, es la apuesta por un nuevo modelo productivo en el que la pieza esencial sean los agricultores. Sin agricultores, las Huertas no subsistirán y no habrá agricultores sin un modelo productivo asentado en una agricultura de proximidad que sea rentable y capaz de transitar desde una orientación tradicional hacia un nuevo modelo agroalimentario liderado por una nueva generación de agricultores. La falta de instrumentos de ordenación y gestión a escala metropolitana, las inciertas expectativas de futuro para la actividad agropecuaria y las dificultades de relevo generacional, aconsejan una acción decidida y distinta de las acometidas hasta ahora.

El retroceso de las Huertas sería la expresión del fracaso colectivo de una sociedad que habría dilapidado en poco tiempo una herencia secular de recursos, de saberes y de civilización (Mata, 2012). Además, se estaría negando la 
posibilidad de contar con espacios estratégicos para la producción de alimentos de forma sostenible y segura. Por eso precisamos de políticas públicas y medidas legales eficaces, coherentes y sostenibles, al tiempo que es imprescindible un mayor grado de información y de concienciación de la ciudadanía. El futuro del territorio y del paisaje depende en gran parte del compromiso de las administraciones púbicas competentes y de una vigorosa sociedad civil que sea capaz de mirar al pasado y hacia el futuro con respeto y sensibilidad.

En este trabajo hemos sugerido algunas recomendaciones que podrían ayudar a revertir las consecuencias de las agresiones perpetradas a las Huertas. Sin duda, la iniciativa que no admite más demora es la adopción de planes territoriales metropolitanos que tomen en cuenta la importancia de la agricultura y de los agricultores, que incorporen un mayor grado de coherencia en la formulación de políticas públicas y que garanticen el fortalecimiento de los instrumentos propios de un nuevo modelo de gobierno del territorio.

Creemos que en el caso de Valencia se están dando las condiciones propicias para avanzar en esa dirección. Sin embargo, en cuanto a Murcia, la continuidad en los gobiernos autonómico y local del Partido Popular augura políticas y posicionamientos en línea con los que se han dado a lo largo de las últimas décadas, a pesar de las acciones y movilizaciones llevadas a cabo por diversas asociaciones de vecinos y colectivos que abogan por la defensa de la Huerta, como Huermur. Mientras que el nuevo alcalde de Murcia anuncia su intención de elaborar un plan de recuperación y conservación de la huerta, se autorizan obras en terrenos protegidos por el Plan general (La Opinión de Murcia, 2015a; 2015b).

Lo cierto es que la mayor concienciación de la ciudadanía acerca de los problemas relativos a las Huertas mediterráneas y las medidas necesarias para su protección no ha hecho sino aumentar en los últimos quince años. Y lo estamos presenciando en Valencia. Tras las grandes movilizaciones en 2001 que acompañaron a la iniciativa legislativa popular, antes citada, y que cristalizaron en la constitución de la plataforma ciudadana Per l'Horta, las protestas populares en favor de la Huerta se reavivaron en 2015 a raíz, especialmente, de las reacciones de rechazo que suscitó el proyecto de reforma del Plan General de Ordenación Urbana de la ciudad de Valencia anunciado en diciembre de 2014. El Plan, ampliamente criticado por urbanistas, agrónomos y académicos locales e internacionales, preveía la reducción de 415 hectáreas de superficie de la Huerta y facilitaba la construcción de 17.000 viviendas nuevas, además de otras infraestructuras (Vázquez, 2014a, 2015a, 2015b, 205c, 2015d; García, 2015). Decenas de organizaciones de la sociedad civil, vertebradas alrededor de la campaña Horta és Futur, presentaron más de 20.000 alegaciones contra el Plan durante el periodo de información pública, demostrando así el compromiso cívico y vecinal ante los atropellos urbanísticos que amenazan el futuro de la 
Huerta. Incluso el Tribunal de las Aguas de Valencia presentó una alegación enfatizando el daño que el nuevo Plan causaría a los sistemas de regadío. El resultado de esta enorme presión social fue la retirada del Plan por parte del Ayuntamiento de Valencia en mayo de 2015. Con ello se puso de relieve, una vez más, que la sociedad civil va muy por delante de los poderes públicos en la defensa del territorio. También en los medios de comunicación se observa un mayor interés y protagonismo de los temas relacionados con la Huerta (Levante, 2015; Vázquez, 2015c; Ros, 2015).

El mapa político configurado tras las elecciones autonómicas y municipales de mayo de 2015, que ha cristalizado en un gobierno local y autonómico formado por una coalición de la izquierda plural, puede dar paso a una forma de hacer política que sea más participativa y más coherente en todas las cuestiones que afectan al territorio. El actual ejecutivo autonómico ha manifestado su intención de impulsar una nueva política del territorio con carácter supramunicipal, empezando por la recuperación del Plan de Acción Territorial de la Huerta (Domingo, 2015), arrinconado hace años por falta de voluntad política del gobierno precedente. Otro actor político fundamental, el ayuntamiento de Valencia, ha pasado de ser el mayor obstáculo para establecer mecanismos de ordenación y gestión a ser uno de los mejores aliados para garantizar el futuro de la Huerta. De existir voluntad política, la Huerta de Valencia podría contar con un marco legal básico de protección y ordenación antes de mediados de 2016. En caso contrario, podrá perderse toda una legislatura.

En consecuencia, lejos de pretender ser triunfalistas, dado que pensamos que los retos e incertidumbres persisten, conviene mantener el nivel de exigencia hasta ahora demostrado ante los poderes públicos. Para que sea eficaz, el Plan deberá realizarse a través de un proceso participativo que atienda a las preocupaciones de la ciudadanía y que otorgue un mayor protagonismo a todos los actores sociales involucrados. Y habrá de conceder mayor relevancia a la agricultura y a los agricultores. En este sentido, el trabajo ya realizado que dio lugar a la redacción del Plan de Acción Territorial de la Huerta de Valencia y la agenda y las alegaciones que desde hace años proponen colectivos ciudadanos como Per l'Horta que defienden un nuevo modelo de gestión de las Huertas para garantizar su supervivencia con criterios sostenibles puede ser un buen punto de partida (Gavaldà y Bayona, 2010; Per l'Horta, 2014). Estas medidas también podrían reforzarse con la inclusión de las Huertas en la lista de Patrimonio Mundial de la UNESCO, como se ha hecho con otros paisajes culturales españoles (Mateu, 2014). El valor de las Huertas trasciende los intereses locales y regionales; su protección es una cuestión de importancia universal. Aparece, así, un horizonte más prometedor, si bien aún incierto, en relación con las estrategias futuras de protección de la Huerta de Valencia. Y esta es, muy probablemente, la última oportunidad para garantizar la supervivencia de 
aquella parte de Huerta que recibimos como herencia y tenemos obligación de dejar como legado.

\section{BIBLIOGRAFÍA}

ANTROP, M. (1997) The concept of traditional landscapes as a base for landscape evaluation and planning. The example of Flanders Region, Landscape and Urban Planning, 38, pp. 105-117.

Argyelan, T., Díez, I., Vallés, M. \& Galiana, F. (2014) Land use change in Huerta de Valencia (2008-2013). Resilience and cultural landscapes, en: C. Sanchis-Ibor, G. Palau-Salvador, I. Mangue \& L. P. Martínez-Sanmartín (Eds) Irrigation, Society and Landscape. Tribute to Thomas F. Glick, pp. 910-923 (Valencia: UPV).

Barbera, G. \& Collotta, S. (2012) An inventory approach to the assessment of main traditional landscapes in Sicily (Central Mediterranean Basin), Landscape Research, 37, pp. 539-69.

Beltrán, J. P. (2012) El desafío global de la producción de alimentos y l'Horta de Valencia, en: J. Romero \& M. Francés (Eds) La Huerta de Valencia. Un Paisaje Cultural con Futuro Incierto, pp. 173-196 (Valencia: PUV).

Burriel, E. (1971) La Huerta de Valencia, Zona Sur. Estudio de Geografía Agraria (Valencia: Institución Alfonso el Magnánimo).

Cárcel-García, C., Verdejo, P. \& Clemente, D. (2014) Molino de Llovera, patrimonio de la arquitectura tradicional de la Huerta de Valencia, en: C. Sanchis-Ibor, G. Palau-Salvador, I. Mangue \& L. P. Martínez-Sanmartín (Eds) Irrigation, Society and Landscape. Tribute to Thomas F. Glick, pp. 1171-1186 (Valencia: UPV).

Comité Económico y Social Europeo (2004) Dictamen del Comité Económico y Social Europeo sobre la agricultura periurbana. Bruselas, 16 de septiembre.

Cortina, J. \& ZAPATA, M. (1993) Los cambios en la articulación entre la huerta y la ciudad de Murcia, Areas. Revista de Ciencias Sociales, 15, pp. 173-190.

Courtot, R. (1986) Agriculture irriguée et organisation ou l'espace dans les huertas de Valencia et de Castellon. (Paris: Université Paris VII).

Domingo, I. (2015): Per l'Horta pide a la consellería que el plan de protección de la huerta incluya a los agricultores, Las Provincias, 9 de octubre.

García, H. (2015) La Universitat de València pide a Barberá que retire el PGOU y preserve la Huerta, Levante, 4 de marzo.

GavaldÀ, J.; Bayona, V. (2010): El Pla d'Acció Territorial de l'Horta: protecció del territori o reserva del sol per urbanitzar? Una anàlisi de la superficie i conexions del PATH, València, 15 de noviembre de 2010.

Generalitat Valenciana (2008) Plan de Acción Territorial de Protección de la Huerta de Valencia. Versión preliminar para la consulta y participación pública. Documento Síntesis. Valencia: Conselleria de Medi Ambient, Aigua, Urbanisme i Habitatge.

Giacché, G. \& Mazzocchi, C. (2011) Gli instrumenti de pianificazione territoriale in relazione alla funcionalità dell'agricoltura periurbana, Projet de paysage, p. 21. Disponible en www.projetsdepaysage.fr

GLICK, T.F. (1970) Irrigation and Society in Medieval Valencia (Cambridge: Cambridge University Press). 
Instituto Geológico y Minero de España (1985): Calidad y contaminación de las aguas subterráneas en España.

Instituto Geológico y Minero de EspaÑa (1998): Mapa del contenido de nitratos en las aguas subterráneas de España.

La Opinión de Murcia (2015a) Ballesta quiere convertir la huerta en el eje central del turismo del municipio, La Opinión de Murcia, 15 de julio.

La Opinión de Murcia (2015b) Cambiemos pide parar las obras de una gasolinera en la huerta, La Opinión de Murcia, 25 de septiembre.

Martí, P. \& Moreno, E. (2014) La transformación urbana y territorial de la ciudad de Murcia y su entorno (1977-2010), Estudios Geográficos, LXXV, 276, pp. 261-309.

Mata, R. (2011) Una agricultura viva para un paisaje periurbano de calidad, en: Catalogue of Good Practices for the Landscape in Periurban Areas and Third Edition of the Mediterranean Landscape Award 2011 (Pay.Med Urban Project 2007-2023), pp. 1-6 (Murcia: Consejería de Obras Públicas y Ordenación del Territorio).

MatA, R. (2012) ¿Por qué proteger hoy la Huerta de Valencia? en: J. Romero \& M. Francés (Eds) La Huerta de Valencia. Un Paisaje Cultural con Futuro Incierto, (Valencia: PUV).

MatA, R. \& Fernández, S. (2010) Paisajes y patrimonios culturales del agua. La salvaguarda del valor patrimonial de los regadíos tradicionales, Scripta Nova, XIV, 337, pp. 1-9.

Mateu, J. (2014) Los paisajes culturales patrimonio mundial como herramientas de gestión territorial. El caso de la Serra de Tramuntana de Mallorca, Boletín de la Asociación de Geógrafos Españoles, 66, pp. 253-270.

Montiel, A. \& García de Leonardo, E. (2014) VII Programa General de Acción de la Unión Europea en materia de Medio Ambiente 2014-2020 y Huerta de Valencia, en: C. Sanchis-Ibor, G. Palau-Salvador, I. Mangue \& L. P. Martínez-Sanmartín (Eds) Irrigation, Society and Landscape. Tribute to Thomas F. Glick, pp. 1038-1053 (Valencia: UPV).

Moreno, J. A., Fernández, P. J. \& Moreno, Á. (2010) La red de regadío de la huerta de Murcia: el Molino de Oliver y el movimiento pro-patrimonio, Áreas, 29, pp. 169-175.

MuÑoz, A. (2009) The Protection Plan for the Valencian Huerta. Comunicación presentada en la conferencia Metropolitan Landscapes, noviembre.

Parc Agrari del Baix Llobregat, Agroterritori \& Red Agroterritorial (2010) Carta de la Agricultura Periurbana. Disponible en http://www.agroterritori.org/ web2/wp-content/uploads/2014/05/Carta-de-la-Agricultura-periurbana.pdf

Per L'Horta (2014): Sis claus per al futur de l'Horta amb 5 propostes d'acció concretes, documento disponible en la web.perlhorta.info

Prats, J. (2003) Estratègies per al Desenvolupament Sostenible (Barcelona: Generalitat de Catalunya).

RodRíGUEZ, R. \& ViCENTE, J. (2009) Planeamento urbanístico municipal e ordenamento do territorio metropolitan, en: X.M. Souto (ed.) Áreas Metropolitanas Galegas, pp. 333-382 (Santiago de Compostela: Xunta de Galicia). 
Romero, J. (2009) Geopolitica y Gobierno del Territorio en España (Valencia: Tirant Lo Blanch).

Romero, J. \& FArinós, J. (2012) Cities and urban and metropolitan regions in Spain: A new agenda in a global context, en: J. Seixas \& A. Albet (Eds) Urban Governance in Southern Europe, pp. 123-148. (Farnham: Ashgate).

Romero, J \& Francés, M. (Eds.) (2012) La Huerta de Valencia. Un Paisaje Cultural con Futuro Incierto (Valencia: PUV).

Romero, J.; JimÉneZ, F.; Villoria, M. (2013): (Un)sustainable territories: causes of the speculative bubble in Spain (1996-2010) and its territorial, environmental, and sociopolitical consequences. Environment and Planning C: Government and Policy, 30(3), 2012, pp. 467-486.

Ros, M. (2015) Rodear Valencia en bicicleta para reivindicar la huerta, Levante, 13 de marzo.

Stanners, D. \& Bourdeau, P. (Eds.) (1995) Europe's Environment: The Dobris Assessment (Copenhagen: European Environmental Agency).

VÁzQuez, C. (2014) Valencia reclasificará 415 hectáreas de huerta para construir 17.000 viviendas, El País, 12 de diciembre.

VÁzQuez, C. (2015a) 20.000 alegaciones contra la pérdida de huerta en Valencia, El País, 25 de febrero.

VÁzQuez, C. (2015b) El paisajista Steinitz defiende desde Harvard la huerta de Valencia, El País, 26 de febrero.

VÁzQuez, C. (2015c) Rebelión en la huerta, El País, 28 de febrero.

VÁzQuez, C. (2015d) La huerta da esquinazo al ladrillo, El País, 12 de mayo.

Vos, W. \& Meekes, H. (1999) Trends in European cultural landscape development: Perspectives for a sustainable future. Landscape and Urban Planning, 46, pp. 3-14. 